\author{
Crossing the Border: International Journal of Interdisciplinary Studies \\ Volume 3; Number 1; 15 January 2015 \\ ISSN 2350-8752 (Print); ISSN 2350-8922 (Online)
}

\title{
NATIONAL GEOGRAPHIC MAGAZINE AND THE POWER OF MEDIA: HOW AN ELITE SOCIETY INFLUENCED AMERICAN PERCEPTION
}

Michelle Welsch (USA)

\begin{abstract}
The history of the National Geographic Magazine has largely evaded the same readers who have adored its editions. Originally intended as a private platform for a select group of white bureaucrats and Washington-D.C. elite, the National Geographic Society achieved commercial success once it included the general public. In time, its publications made foreign lands and scientific discovery accessible to the masses. The magazine's articles thrilled the American audience as readers could browse foreign destinations from the safety of their homes. Fascination with the elite combined with powerful platforms of photography and text influenced perception of portrayed subjects. "Exotic" topics established a division between observer and the observed, and published content revealed undertones of racial and gender hierarchy. Early editions provide evidence that caution reader of the impact media can have both on and within cultures and the accompanying importance of questioning the intent of publications.
\end{abstract}

KEYWORDS: Media, National Geographic, elite society, ethnography, American perception, culture

\section{INTRODUCTION}

Cinema, radio, television, print and Internet portray ways of seeing and analyzing the world, shaping perception and interpretation within - and of - a particular society. Such media forms are powerful transmitters of culture. Debra Spitulnik observed that mass media is "at once cultural products and social processes, as well as extremely potent arenas of political struggle" (1993). It is necessary to question publications and their intended purpose, especially those with the success and reach of National Geographic Magazine.

Since its inception, the National Geographic Society has become a mainstream force, tinting American consideration of foreign lands and contemporary science. The influence of the magazine on American perception cannot be debated. Dubbed "the lens through which America views the world," the company's magazine has gained cultural power through an international readership of millions (Thompson, 2000). Its origins, however, and the founders' intended mission offer fodder for discourse.

Originally designed as an exclusive platform for scholars, the Society was comprised of elite, white professional men. How did this exclusive group evolve into a widely successful media form, and what effect has it had on perception of foreign places and people? With over a century of publication, the magazine lends itself to investigation. 


\section{Crossing the Border: International Journal of Interdisciplinary Studies \\ ORIGINS}

After the American Civil War, intellectual fervor swept the United States. Various organizations catered to growing interest in research and discovery, and the scientific community blossomed (Schulten, 2000). In 1888, a group of government officials, prominent businessmen and scientists established an organization similar to Britain's Royal Geographical Society. The men wanted a platform in which they might discuss trends and developments in science, and they wanted to publish discoveries in the field (Poole, 2004). Most importantly, they wanted to influence America's political sphere, gain popularity among the educated class, and steer the policies of America's developing nation.

A group of thirty-three men envisioned an exclusive setting for regular discourse and a private community dedicated to scientific pursuit. Unanimously, they agreed upon a membership-only organization. As a result, the National Geographic Society was devised "for increase and diffusion of geographic knowledge" (Poole, 2004). Certain participants were nominated to topical categories and given responsibility for organizing lectures that would later be written as magazine articles. Strict membership guidelines regulated nomination through existing members only, and a committee board approved all potential candidates.

The magazine, for which the Society would later come to be known, was not an immediate focus. Regular publications emerged almost one year after the Society's original development, circulating among its one hundred and sixty-five charter members (Grosvenor, 1988). Early publications were drab and complicated, filled with letters, diagrams and educational models. Black and white copies emphasized empirical rigor, depicting research tools and notes from the Society's lecture series. Laypeople had difficulty understanding the published jargon; for instance, an article on hydrology instructed, "Let AB, fig. 9, be a stream whose initial consequent course led it down the gently sloping axial trough of a syncline" (Davis, 1889). Anecdotes and photos were discouraged, and little attempt was made to attract new readers (Schulten, 2000). Only later would general interest topics and photographs be dispersed throughout the magazine's pages.

\section{ELITE INFLUENCE}

The Society's first president, Gardiner Greene Hubbard, was a wealthy attorney known for his sponsorship and endorsement of scientific quests. He envisioned membership would be open to influential political, military and government leaders. Other members balked at the idea of including everyday citizens. Through an assortment of marriages, the Society remained a family-dominated business. When Hubbard died, his son-in-law Alexander Graham Bell acquired the magazine and assumed all corresponding responsibilities. By this time, the operation was plummeting fiscally.

Although readership ballooned to almost 1,500 subscribers, the Society could not attract additional members (Bruce, 1973). Bell himself labeled the magazine as "a valuable technical journal that every one put upon his library shelf and a few people read. It was valuable...but it did not contribute anything to the financial support of the Society" (1912). The Society was in debt, and pressure to turn the magazine into a commercial operation surfaced.

Bell knew he needed to breathe life into the struggling operation. He devised a scheme to circulate publications beyond Washington, D.C.s elite. "The world and 
all that is in it is our theme, and if we can't find anything to interest ordinary people in that subject we better shut up shop and become a strict, technical, scientific journal for high class geographers and geological experts," he asserted (Library of Congress, 1900). He insisted on maintaining a membership-based structure but lowered membership fees and encouraged staff to produce less technical publications. "If you can make the Magazine interesting and entertaining to the general reader, there is no reason why the membership should not reach ten times ten thousand," he implored (Library of Congress, 1905).

Under his direction, the magazine began marketing efforts. The strategy “...make the fact of an election to N.G.S. an honor so that people will think they are complimented by a nomination" worked, and invitation lists were compiled of members of prestigious institutions (Grosvenor, 1988). Noteworthy personalities opened invitations to secret meetings, and members of Phi Beta Kappa, the National Academy of Sciences, the National Education Association, and the American Association for the Advancement of Science received forms printed on embossed letterhead (Poole, 2004). Heavy card stock enticed, "I have the honor of advising you that the Membership Committee extends you a cordial invitation to become a member of the National Geographic Society" (Ross, 1938). In time, blank nomination cards were inserted into magazine editions, politely encouraging members to direct nominations to the board.

Capitalizing on public curiosity and recent developments in science, Bell's advertising campaigns worked. In less than one year, membership doubled; however, not all members were thrilled. Bell's work deviated from the Society's early days of exclusivity. Founders scoffed at readership solicitation, recalling original functions that encouraged "enlightened patriotism" (Hyde, 1896). Several members had known each other since the organization's beginnings and were hesitant to take part in an expanding enterprise. One disgruntled founder left to create the Association of American Geographers; others attempted to reject new member lists in order to maintain a strict upper-class organization (Pauly, 1979).

Unfazed, Bell forged ahead with plans to make the magazine commercially successful. "I see no reason why our mag. [sic.] should not be of great popular interest, and grow...there is no harm in having a high ideal, even though it may be beyond the feasibility of actual realization," he said (Library of Congress, 1899). He used family money to secure a permanent location for the Society and generated revenue through formal banquets and elaborate dinners. Presidents, senators and dignitaries attended these white-tie affairs, and a relationship with the American political scene was maintained through the Society's Washington, D.C.-based headquarters.

As government officials, military men and bureaucrats became further involved with the Society, science and politics became intertwined (Poole, 2004). Presidents wrote articles for the magazine and awarded medals on behalf of the organization for scientific accomplishment (Thompson, 2000). Such affiliations heightened allure and prestige, and the organization became synonymous with elite culture. Advertisements in the Magazine encouraged, "Mention the Geographic - it identifies you" (A notice to the advertisers, 1949).

The acquisition of land following the Spanish-American War fueled American interest in geography and culture. After the war, articles about newly acquired territories filled the magazine: "It is doubtful if the study of any branch of human knowledge ever 


\section{Crossing the Border: International Journal of Interdisciplinary Studies}

before received so sudden and powerful a stimulus as the events of the past year have given to geography," the Society surmised (Hyde, 1899). Combined with the growing popularity of railroad travel, everyday Americans were captivated by foreign lands and cultures. Even the middle-class protagonist in the popular American film "It's a Wonderful Life" boasts, "Only us explorers can get it. I've been nominated for membership in the National Geographic Society!" (Capra, 1946).

With a surplus budget, the Society began funding expeditions. Not only was it considered dignified for members to support professional explorations, such exploits provided rich material for publication (Freeman, 1961). Professionals who viewed the Society as misrepresentative of the scientific community were pacified by the use of fees supporting research, and "arm-chair" novices could now feel part of discoveries previously reserved for aristocrats (Pauly, 1979). As circulation numbers of the magazine rose, the irony became evident: an organization founded as a private society achieved great success as a monthly periodical.

\section{ACCESSIBLE MEDIA}

Americans were transfixed by activities and interests pursued by the elite. Once editions adopted a "general interest approach," the general public seized the opportunity for inclusion (Schulten, 2004). Articles began to feature "fireside" topics such as backyard grasses, local insects, and recounts of sponsored expeditions. Adventure and discovery filled the magazine, inspiring novices to take interest in scientific happenings.

As the magazine introduced readers to new and foreign concepts, the addition of photography captivated readers. Photographs first appeared in a 1905 edition, but the inclusion was not entirely planned. Frantically facing a print deadline, the editor filled an eleven-page deficit with recently acquired images from Tibet (Grosvenor, 1988). No article accompanied the photographs; only brief captions were placed throughout the spread. Much to the editor's relief, the edition was a complete success. In fact, the issue was so popular it had to be returned to print to meet publishing demands (Schulten, 2000).

Five years later, the magazine was producing the largest collection of colored photographs of any periodical in the world (Poole, 2004). Not only was the novelty of photography intriguing, its accessibility encouraged participation from a wide audience. Attractive images turned "man and nature into something close to art. In doing so, the magazine catered to the inquisitive consumer, creating a shimmering, bejeweled place that we yearn to possess" (Thompson, 2000). Image and word became a powerful duo, snaring readers' attention and influencing readers' evaluation of presented material.

The magazine assumed an ethnographic form, blending disciplines of anthropology, pedagogy, and art (Hawkins, 2008). This combination boosted readership, as non-scientists could easily approach scientific subjects through photographs and simplistic captions, and scientists were ensnared by the elite history of the periodical. Slowly, science and photography became intertwined, and the line between fact and fiction blurred.

\section{INFLUENCING PERCEPTION}

Photographs helped readers assimilate new discoveries into pre-existing schemas, and foreign subjects became tangible through the magazine's pages. Through pho- 
tographs, the magazine bridged Americans' conception of the world with new ideas (Jain, 1988). Hall observed,

...the mass media are more and more responsible for providing the basis on which groups construct an 'image' of the loves, meaning, practice, and values of other groups and classes; for providing the images, representations and ideas around which the social totality, composed of all these separate and fragmented pieces, can be coherently grasped as a whole. (1977)

In the name of scientific objectivity, the magazine claimed to portray subjects in authentic environments, yet individual photographs often became representative of entire groups of people. From 1905 until about 1920, countries featured in magazine articles exhibited characteristics distinctly different from American culture. Early in the magazine's history, a hierarchical consideration of culture was established. "If parallels of latitude were drawn around the earth about fifteen degrees north and fifteen degrees south of Washington, the land within these parallels would include all the countries of the world that have been highly civilized and distinguished for art and science," the Society's president noted (Hubbard, 1894).

For Americans sitting in their living rooms, the magazine offered a portal into the unknown (Runte, 1992). Foreign lands were presented particularly for the "arm-chair" tourist by focusing on positive characteristics of remote places (Raub, 1988). Articles romanticized distant places, even describing the American Southwest in a way that might be confused with a romance novel: “... awaits the quickening kiss of canal-borne water to yield abundant harvest and to provide homes for millions" (Blanchard, 1909).

American immigrants used the magazine to learn about their new homeland, and Americans read the magazine to learn about their new residents. Articles on American immigrants mirrored the way in which individuals were described in developing countries - material for the at-home scientist (Raub, 1988). When African Americans were mentioned, they were depicted as refined citizens: waiters, chauffeurs and hosts. As anxieties regarding incoming ethnicities and their inclusion into American society began to surface, articles on insects and pest control implied reference when featured alongside discussions on immigration control and eugenics (Hawkins, 2008). Without apology, a Society president wrote, "This flood of immigration has lowered the average intelligence and morality of the community" (Gannett, 1897).

\section{PORTRAYAL OF "EXOTIC"}

People and places described as "exotic" tempt audiences with adventure and intrigue. Since early exploration, the notion of the "exotic" has captivated minds. The magazine capitalized on this. Inherently, the portrayal of "exotic" is not designed to be realistic but "a blend of myth and fable" (Knellwolf and McCalman, 2002).

By introducing foreign cultures to the American people, the magazine attempted to create awareness of the world and its many cultures. However, as one culture is introduced to another, a dynamic between observer and the observed is established (Knellwolf and McCalman, 2002). American culture became the standard by which others were judged as readers viewed themselves in contrast to the perceived differences of those depicted in photographs and articles (Bloom, 1994). "Native traditions and photographic accuracy are given as a rationale to support a particular definition of nation, ethnicity, and sexuality in which being 'American' is being one of 'us' --- 


\section{Crossing the Border: International Journal of Interdisciplinary Studies}

white and male --- as opposed to one of 'them,' nonwhite and female" (Bloom, 1994).

Elizabeth Bishop was waiting in a dentist's office when she encountered the magazine as a young child. Her poem "In the Waiting Room" describes her experience. She writes:

while I waited and read/ the National Geographic/ (I could read) and carefully/ studied the photographs:/ the inside of a volcano,/ black, and full of ashes;/ then it was spilling over/ in rivulets of fire...A dead man slung on a pole/ "Long Pig," the caption said./ Babies with pointed heads/ wound round and round with string;/ black, naked women with necks/ wound round and round with wire/ like the necks of light bulbs./ Their breasts were horrifying./ I read it right straight through./ I was too shy to stop./ And then I looked at the cover:/ the yellow margins, the date...I might have been embarrassed,/ but wasn't. What took me/ completely by surprise/ was that it was me:/ my voice, in my mouth...I felt in my throat, or even/ the National Geographic/ and those awful hanging breasts/ held us all together/ or made us all just one (1979).

Prior to the circulation of pornography of the 1960s, the magazine was one of the first accepted media forms in which nude images could be found (Blackmer, 1998). Since editorial policy forbade negativity and partisanship, naked female bodies were presented as natural and respectable (Blackmer, 1998). By displaying partially nude non-white women, the magazine eroticized third-world cultures (Bloom, 1994). It defended these inclusions with official editorial policy, showing "people dressed or undressed according to the customs of their land" (Bloom, 1994). Such racial and sexual undertones in a publication consumed by American families seem unusual (Thompson, 2000). By asserting science and "ethnography," the magazine freely exhibited dark-skinned young girls and bare-breasted non-white woman (Thompson, 2000).

A fascination with race was revealed through detailed descriptions of physical traits and cultural practices (Hawkins, 2008). Such details broadened the gap between reader and subject. Distance created by the notion of "us" in relation to "them" fails to encourage identification, empathy, recognition or self-awareness (Hawkins, 2008).

\section{CONCLUSION: MEDIA AND ITS IMPACT}

The magazine, at face value, is a captivating publication that has highlighted global practices and scientific pursuit for years. Its yellow-bordered covers bring remote locations to life with a format that has blended "science and spectacle in a way that is purposely reassuring rather than challenging" (Thompson, 2000).

It is important to note the emergence of the magazine in the context of historical times. By the 1880 s, scientists had distanced themselves from novice hobbyists. The separation of specialized science from generalist study provided an ideal backdrop for its success. Despite loose professional status, it acquired fame, permeating pop culture and providing everyday conversation topics. It became a vehicle for middleand upper-middle class Americans to view "exotic" and foreign destinations without leaving the comfort of their homes.

The influence of the early Society can be seen throughout the periodical's long history. An aristocratic, white-male perspective colored articles, influencing the portrayal of foreign subjects and the depiction of minorities and women. As the Society emerged as a badge of culture, the magazine's pages shaped public opinion. 
Whether the public has or has not been aware of its origin and development is a topic demanding additional study.

Is it possible to critically curate and present media for consumption? The act of collecting material to present to an audience is rarely without bias. Butler remarks, "...Curating, like teaching, should never be an authoritative exercise that imposes views on others" (2000). However, it is evident some approaches are stronger than others and result in a stronger impact on viewers and participants.

Consumers will consume, interpreting articles and photographs as they wish. The magazine established itself as a scientific platform and presented material in a way that could evade criticism, and its history evaded the majority of its readers. "Probably the most general --- and most difficult --- question about the place of mass media in modem societies is their implications for fundamental and irreversible social and cultural change" (Spitulnik, 1993). With all media forms, consumers must consider the nature and intent of publication.

\section{REFERENCES}

A notice to the advertisers. (1949). Advertising in the geographic magazine is an exact science. National Geographic Magazine, 25, n.p.

Bell, A.G. (1912). The national geographic society. National Geographic Magazine, 23, 273-4.

Bishop, E. (1976). In the waiting room. In A. H. Methfessel (ed.), The Complete Poems 1927-1979. New York City: Farrar, Straus \& Giroux, Inc.

Blackmer, C. (1998). Ethnoporn, lesbian childhood, and native maternal culture: Reading National Geographic with Elizabeth Bishop. GLQ: A Journal of Lesbian and Gay Studies, 4(1), 17-58.

Blanchard, C. J. (1909). The call of the west. National Geographic Magazine, 20(5), 403-447.

Bloom, L. (1994). Constructing whiteness: Popular science and National Geographic in the age of multiculturalism. Configurations, 2(1), 15-32.

Bruce, Robert V. (1973). Bell: Alexander Graham Bell and the conquest of solitude. Boston: Little, Brown. Reprint, Ithaca: Cornell University Press, 1990.

Butler, S. (2000). The politics of exhibiting culture: Legacies and possibilities. Museum Anthropology, 23(3), 74-92.

Capra, F. (Director). (1946). It's a wonderful life [Motion picture]. New York, NY: Radio-Keith-Orpheum (RKO) Pictures.

Davis, W. M. (1889). The rivers and valleys of Pennsylvania. National Geographic Magazine, 1(3), 183-253.

Freeman, T. W. (1961). A hundred years of geography. Chicago, IL: Aldine.

Gannett, H. (1897). Annexation fever. National geographic magazine, 8(12), 355.

Grosvenor, G. (1988). A hundred years of the national geographic society. The Geographical Journal, 154 (1), 87-92.

Hall, S. (1977). Culture, the media, and the "ideological effect." Mass Communication and Society, ed. .J Curran, M. Gurevitch, J. Woollacott, 315-348.

Hawkins, S. (2008). Savage visions: Ethnography, photography, and local-color fiction in national geographic. The Arizona Quarterly, 64(2), 33-63.

Hubbard, G. G. (1894). Geographic progress in civilization. National Geographic Magazine, 6, 1-22.

Hyde, J. (1896). Introductory: The editor. National Geographic Magazine, 7, 1-2. 


\section{Crossing the Border: International Journal of Interdisciplinary Studies}

Hyde, J. (1899). The national geographic society. National Geographic Magazine, 10, 222. Jain, S. (1998). Mysterious delicacies and ambiguous agents: Lennart Nilsson in national geographic. Configurations, 6(3), 373-394.

Knellwolf, C. \& McCalman, I. (2002). Introduction. Eighteenth-Century Life, 26, 1-9.

Library of Congress. (1899). Grosvenor Family Papers, Gilbert H. Grosvenor to Edwin A. Grosvenor, June 7. Washington, D.C.

Library of Congress. (1900). Grosvenor Family Papers, Alexander Graham Bell to Gilbert H. Grosvenor, Mar. 5. Washington, D.C.

Library of Congress. (1905). Grosvenor Family Papers, Alexander Graham Bell to Gilbert H. Grosvenor, Dec 7. Washington, D.C.

National Geographic Society Archives. (1911). Gilbert H. Grosvenor to Board of Managers, Apr. 19. Washington, D.C.

Pauly, P. (1979). The world and all that is in it: The national geographical society, 1888-1918. American Quarterly, 31, 517-532.

Poole, R.M. (2004). Explorers' house: National geographic and the world it made. New York, NY: Penguin Press.

Raub, P. (1988). The national geographic magazine's portrayal of urban ethnicity: The celebration of cultural plurism and the promise of social mobility. Journal of Urban History, 14(3), 346-371.

Ross, I. (1938). Geography, Inc. Scribner's Magazine, 103(6), 23-27.

Runte, A. (1992). Promoting wonderland: Western railroads and the evolution of national park advertising. Journal of the West, 31, $43-48$.

Schulten, S. (2000). The making of the national geographic: Science, culture, and expansionism. American Studies, 41(1), 5-29.

Spitulnik, D. (1993). Anthropology and mass media. Annual Review of Anthropology, 22(1), 293-315.

Thompson, C. (2000). Neutral gaze? The influence of national geographic magazine. New Statesman, 129(4476), 45-47.

\section{ABOUT THE AUTHOR}

Michelle Welsch is a Licensed Master Social Worker. She graduated magna cum laude from the University of Colorado at Boulder with a B.A. in Psychology and holds a master's degree from Columbia University in New York City with an emphasis on Advanced Clinical Practice and Contemporary Social Issues. She has worked alongside top entrepreneurs and thought leaders in America, consulting Fortune 500 brands and organizing well-reviewed events and conferences. Her blog has attracted over 33,000 views, and her writing has been featured on online platforms such as Fast Company, Exposure, Medium, Elephant Journal and Social Media Week.

Michelle is the founder of Project Exponential, a monthly dinner series that strategically invites guests for professional and personal discourse. She launched Khata: Life based on her efforts to promote education and leadership in Nepal, and her work has received recognition within Kaski District and the broader Nepali community. To learn more visit www.michellewelsch.com. 